\title{
Mixture toxicity in the Erft River: assessment of ecological risks and toxicity drivers
}

\author{
Nele Markert ${ }^{1 *}$ (D) Stefan Rhiem ${ }^{1}$, Michael Trimborn ${ }^{2}$ and Barbara Guhl ${ }^{1}$
}

\begin{abstract}
Background: A vast number of chemical substances are released into the aquatic environment, leading to complex chemical mixtures in surface waters. Current water quality assessments, however, are based on the risk assessment of single substances. To consider potential mixture effects in water quality assessments, the North Rhine Westphalian State Agency for Nature, Environment and Consumer Protection (LANUV), Germany started a project assessing mixture toxicity in surface waters. This article summarises the mixture evaluation of chemical data collected by the Erftverband during a water sampling campaign in the Erft River in 2016/2017. Altogether, 153 substances were included in the analysis, of which 98 were detected. Two different approaches based on the concept of concentration addition were used to analyse the data. The results were compared to findings based on datasets from LANUV surveillance monitoring according to the EU Water Framework Directive.

Results: Acute and chronic mixture risk calculations indicated risks for $32 \%$ and up to $90 \%$ of the samples, respectively. The greatest acute toxic pressure was identified for the aquatic flora due to continuous exposure to varying pesticides, whereas the greatest chronic mixture risk was identified for fish as result of a ubiquitous presence of the pharmaceuticals diclofenac and ibuprofen. Overall, only a limited number of substances significantly contributed to the calculated mixture risks. However, these substances varied seasonally and regionally. When mixture risks were calculated based on different datasets, the monitoring design markedly affected the outcome of the mixture risk assessment. Data gaps of both ecotoxicological and exposure data lead to high uncertainties in the mixture risk assessment.

Conclusions: Ecotoxicological effects on aquatic organisms caused by chemical mixtures can be expected along the Erft River throughout the year. Both mixture risk assessment approaches can be used for a conservative assessment of mixture risks and characterise the aquatic pollution in the river more realistically than single substance assessments. For the integration of mixture risk evaluations into the assessment and management of the chemical water quality, a two-staged assessment combining both approaches is suggested. To improve future risk assessments, the accessibility and exchange of high-quality ecotoxicological data should be enhanced.
\end{abstract}

Keywords: Mixture effects, Toxic units, Surface waters, Chemical monitoring, Toxicity drivers

\section{Background}

A variety of chemical substances originating from different point and diffuse sources of pollution such as agriculture, industry and municipal wastewater treatment plants (WWTP) are released into the aquatic environment daily. These chemical substances are present in complex

\footnotetext{
*Correspondence: nele.markert@lanuv.nrw.de

${ }^{1}$ LANUV NRW, Wallneyer Str. 6, 45133 Essen, Germany

Full list of author information is available at the end of the article
}

mixtures, i.e. seasonally and regionally varying combinations of multiple chemicals that may contribute to a joint mixture toxicity for aquatic organisms [1]. Regulatory risk assessment of chemicals, however, is mainly based on the assessment of single substances. In particular, unintentional mixtures of chemicals originating from discharge during production, transport, usage or disposal of chemicals are yet only rarely addressed in regulation [2]. Several publications from both the scientific and the regulatory communities have stated concern about the risks
SpringerOpen

(C) The Author(s) 2020. This article is licensed under a Creative Commons Attribution 4.0 International License, which permits use, sharing, adaptation, distribution and reproduction in any medium or format, as long as you give appropriate credit to the original author(s) and the source, provide a link to the Creative Commons licence, and indicate if changes were made. The images or other third party material in this article are included in the article's Creative Commons licence, unless indicated otherwise in a credit line to the material. If material is not included in the article's Creative Commons licence and your intended use is not permitted by statutory regulation or exceeds the permitted use, you will need to obtain permission directly from the copyright holder. To view a copy of this licence, visit http://creativeco mmons.org/licenses/by/4.0/. 
chemical mixtures might pose, even when all substances occur at low concentrations at or below each respective predicted no effect concentration (PNEC) [3-9]. Furthermore, they emphasised the need for harmonised scientific and regulatory approaches for mixture risk assessment and the identification of substances acting as main drivers of mixture effects $[4-7,9]$.

Potential mixture effects have so far not explicitly been considered in water quality assessments in North Rhine Westphalia (NRW), Germany. To implement scientific approaches on mixture toxicity, and thereby, improve the current water quality assessments, the North Rhine Westphalian State Agency for Nature, Environment and Consumer Protection (LANUV) started a project assessing mixture toxicity in surface waters using data from chemical monitoring, on behalf of the Ministry for Environment, Agriculture, Conservation and Consumer Protection of the State of North Rhine-Westphalia (MULNV).

There are two mathematical models that have commonly been used for the assessment of ecotoxicological effects of defined chemical mixtures: (1) concentration addition (CA) assuming a similar mode of action (MoA) of the individual compounds of a mixture, and (2) independent action (IA) based on the assumption of dissimilar MoAs [10-13]. In general, both models predict mixture effects in a similar order of magnitude with CA being assumed to be a more conservative approach [14-16]. The CA model usually enables predictions close to observed mixture effects and can be used for a conservative estimation of mixture toxicity even if mixtures contain substances with dissimilar or unknown MoA [16-18]. Furthermore, CA only requires data on the environmental concentration and the ecotoxicological effect concentration (ECx), whereas for IA information on the MoA of the compounds as well as detailed knowledge on the complete dose-response curves are imperative [10, 11]. Stronger deviations from both models, such as those caused by synergism, are rarely expected to occur at environmentally relevant concentrations [19]. Therefore, the $\mathrm{CA}$ model can be used as a pragmatic and protective model assessing the effects of environmental mixtures $[11,20,21]$.

In the present study, two CA-based risk assessment approaches were applied to datasets from the Erft River: (1) summation of Toxic Units (TU) and (2) summation of risk quotients $(\mathrm{RQ})$ of the individual mixture components (c.f. Backhaus and Faust [10]). Two chemical datasets from the Erft River were evaluated, i.e. an extensive monitoring program from the Erftverband in 2016/2017 as well as data from the EU Water Framework Directive (WFD) surveillance monitoring undertaken by LANUV. The data were analysed for seasonal variability and spatial trends along the Erft River. Moreover, difference in mixture risks between the biological groups of algae, macrophytes, aquatic invertebrates and fish as well as substances potentially acting as drivers of mixture toxicity was identified. The results of both approaches are compared with regard to the information generated and with respect to the applicability to data from routine monitoring.

\section{Methods}

\section{Sampling site and sampling campaign}

The Erft River is located in the Southwest of NRW, Germany with its source in the low mountain range of the Eifel close to the city Bad Münstereifel and its confluence into the river Rhine south of the city Neuss. The Erft River has a length of $104 \mathrm{~km}$ and a total catchment area of $1918 \mathrm{~km}^{2}$. The upper part of the catchment area is mainly characterised by forest and grassland ( $43 \%$ and $29 \%$, respectively), whereas the middle and lower reaches are increasingly influenced by intensive agriculture $(47-57 \%)$ as well as urban and industrial areas (17-22\%) [22, 23]. All in all, the Erft catchment area has a high population density of 665 inhabitants per square kilometre [24]. An additional influencing factor is active and former lignite mining in the lower reaches and the associated discharge of drainage water from the mines. Therefore, the Erft River and its tributaries are exposed to a wide range of chemical substances.

From March 2016 to March 2017, surface water samples were taken in 13 sampling campaigns at 39 sampling sites along the Erft River and seven tributaries (Veybach, Swist, Rotbach, Neffelbach, Finkelbach, Gillbach and Norfbach; Fig. 1). Four samplings were performed after rain events and nine during dry weather conditions. For the Erft River, sampling sites were located at the river source, up- and downstream of seven WWTP, and upand downstream of the tributaries mentioned above. Furthermore, samples were taken in each of the tributaries mentioned above as well as up- and downstream of three additional WWTP located in tributaries of the Erft River.

\section{Chemical analyses of surface water}

Surface water samples were analysed for a total of 153 substances (Additional file 1: Table S1 1-3), including 100 pesticides, 41 pharmaceuticals and 12 other substances, by high-performance liquid chromatography coupled with tandem mass spectrometry (HPLC-MS/ MS) as well as gas chromatography coupled with tandem mass spectrometry (GC-MS/MS). Some substances were included later during the sampling campaign: penconazole, 4-methyl- $1 H$-benzotriazole, gabapentin and metformin (May 2016) as well as azithromycin, chlortetracycline, ciprofloxacin, clindamycin, doxycycline and oxytetracycline (Sept. 2016). Grab samples of surface water were stored in 1-L amber glass bottles and cooled during transportation. Ten samples were taken 


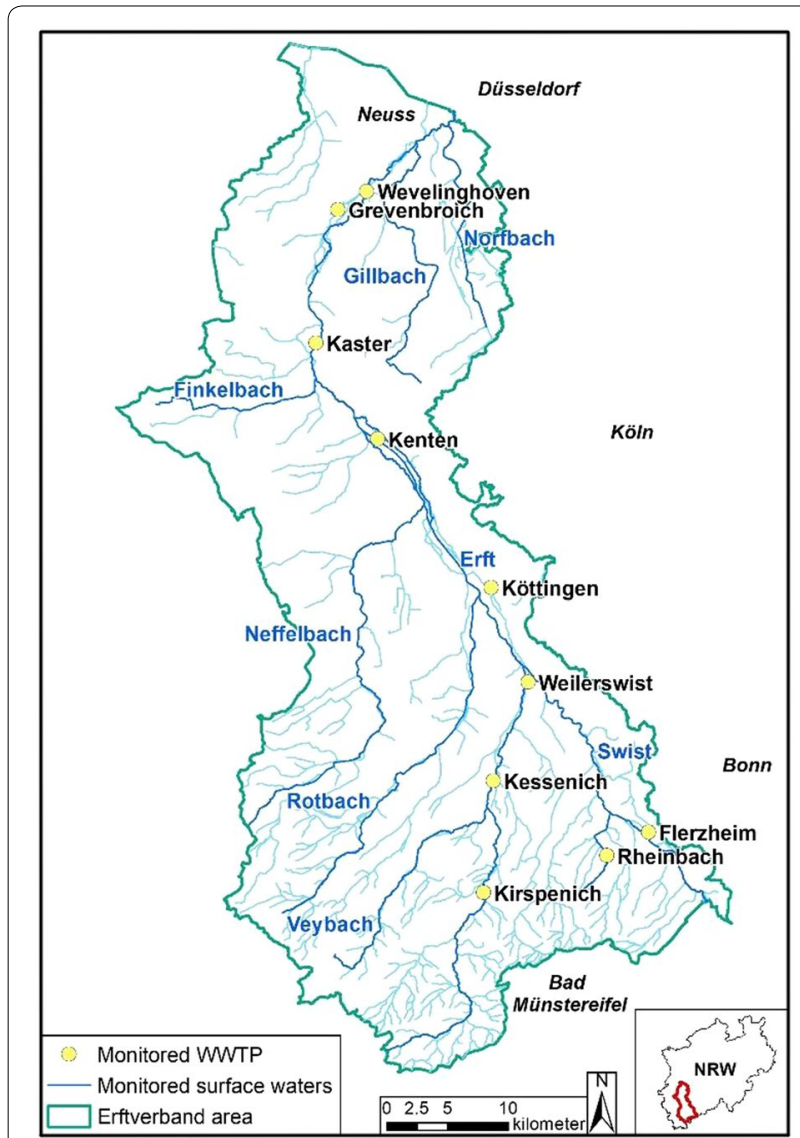

Fig. 1 Map of the study area in the River Erft, Germany in 2016/2017

as 24-h volume-proportional composite samples using stationary automated samplers at two of the sampling sites only (Swist and Erft downstream of the Veybach). At the laboratory, samples were immediately filtered through glass-fibre filters (MN GF-6, Macherey-Nagel, Düren, Germany). A total of $50 \mathrm{~mL}$ of each filtered sample were prepared for HPLC-MS/MS by addition of $50 \mu \mathrm{L}$ of formic acid (VWR International GmbH, Darmstadt, Germany) and stored separately in $50-\mathrm{mL}$ amber glass bottles. For GC-MS/MS, a 500-mL aliquot of each sample was spiked with $100 \mu \mathrm{L}$ of GC-MS/MS internal standard solution (Additional file 1: Table S1-5) and acidified with hydrochloric acid (25\%, w/v, Merck KGaA, Darmstadt, Germany; pH $2 \pm 0.2$ ). Samples were stored for a maximum of 14 days before analyses.

For HPLC-MS/MS analyses using Agilent 1260 Infinity LC with Agilent 6460 Triple Quadrupol MS, $1000 \mu \mathrm{L}$ of the prepared water samples were each spiked with $10 \mu \mathrm{L}$ of the internal standard solution (Additional file 1: Table S1-4) and analysed without further modification in accordance to the German standard method (DIN 38407-36:2014-09).
GC-MS/MS analyses were performed using Thermo GC Trace 1310 with MS TSQ 8000 Triple Quadrupole according to the German standard method DIN EN ISO 15913:2003. The prepared sample aliquots were extracted by filtration through pre-conditioned $(3 \times 2 \mathrm{~mL}$ acetone, $3 \times 2 \mathrm{~mL} 0.01 \mathrm{~mol} / \mathrm{L} \mathrm{HCl}$; VWR International $\mathrm{GmbH}$, Darmstadt, Germany) solid phase extraction (SPE) cartridges (OASIS $\mathrm{HLB}^{\circledR} 3 \mathrm{~mL} / 60 \mathrm{mg}$ sorbent/cartridge; Waters $\mathrm{GmbH}$, Eschborn, Germany). The cartridges were washed with $2 \mathrm{~mL} 0.01 \mathrm{~mol} / \mathrm{L} \mathrm{HCl}$ and dried under a nitrogen stream. Analytes were eluted with $5 \mathrm{~mL}$ acetone into disposable glass reagent tubes. The eluate was dried under a nitrogen stream at room temperature, and then $50 \mu \mathrm{L}$ trimethylsilyl-diazomethane solution (SigmaAldrich Chemie GmbH, Munich, Germany) and $250 \mu \mathrm{L}$ methanol (Merck KGaA, Darmstadt, Germany) were added to each of the eluates. After standing overnight, the excess reagent was removed by a nitrogen stream and the dry residue was re-dissolved in $250 \mu \mathrm{L}$ toluene (Merck KGaA, Darmstadt, Germany). Detailed HPLCMS/MS and GC-MS/MS conditions and calibration methods are described in Additional file 1: Table S1 6-7.

\section{Ecological risk assessment}

Ecological risks of the substance mixtures in the Erft River were assessed using two CA-based approaches. Both are described by Backhaus and Faust [10] and referred to as $R Q_{\text {mix }}$ and $S U M R Q$.

The first concept for the mixture risk assessment, $R Q_{\text {mix }}$, is based on the TU approach. TUs were calculated for each substance $i$ as a quotient of the MEC and the effect concentrations from standardised bioassays for the biological groups of algae, macrophytes (MP), aquatic invertebrates (Inv) and fish:

$$
\mathrm{TU}_{i}=\mathrm{MEC}_{i} / \mathrm{ECx}_{i} .
$$

Subsequently, the TUs of the individual substances of the $n$-compound mixture in a sample were summed up to SUM TUs for each biological group (SUM TU Algae, SUM TU $\mathrm{MP}_{\mathrm{MP}}, \mathrm{SUM} \mathrm{TU}_{\mathrm{Inv}}$, $\left.S \mathrm{UM} \mathrm{TU}_{\mathrm{Fish}}\right)$ :

$$
\text { SUM TU }=\sum_{i=1}^{n} \mathrm{TU}_{\mathrm{i}} .
$$

The $\mathrm{RQ}_{\text {mix }}$ was then calculated based on the SUM TU of the most sensitive biological group using an assessment factor (AF):

$$
\mathrm{RQ}_{\text {mix }}=\max \left(\mathrm{SUM}_{\mathrm{TU}} \mathrm{U}_{\mathrm{Algae}}, \mathrm{SUM} \mathrm{TU}_{\mathrm{MP}}, \mathrm{SUM} \mathrm{TU}_{\mathrm{Inv},}, \mathrm{SUM} \mathrm{TU}_{\mathrm{Fish}}\right) \cdot \mathrm{AF} .
$$

Although most studies have focused on the assessment of long-term mixture risks based on acute toxicity data, there is evidence that risks can also be assessed by 
CA-based approaches using chronic toxicity data [25, 26]. Thus, chronic mixture risks were calculated in the present study using the $R Q_{\text {mix,1000 }}$ based on acute toxicity data as described by Backhaus and Faust [10]. In addition, risks were calculated based on chronic toxicity data $\left(\mathrm{RQ}_{\mathrm{mix}, 10}\right)$. The AFs were applied according to the technical guidance document for deriving environmental quality standards [27] and set to an $A F$ of 1000 for $R_{\text {mix,1000 }}$ and an $\mathrm{AF}$ of 10 for $\mathrm{RQ}_{\mathrm{mix}, 10}$. Moreover, to assess acute mixture risks the $R Q_{\text {mix,acute }}$ was calculated based on the acute toxicity data using an AF of 100.

Acute and chronic effect concentrations (i.e. $\mathrm{EC}_{50} / \mathrm{LC}_{50}$ and $\mathrm{EC}_{10} / \mathrm{LC}_{10} / \mathrm{NOEC}$, respectively) originated from validated experimental data from toxicity tests following established guidelines [27]. In accordance with the concept of CA, experimental data were preferably used from tests with the same test endpoint, duration and standard test species (Raphidocelis subcapitata, Lemna gibba, Daphnia magna, Oncorhynchus mykiss). This, however, might lead to an underestimation of risk if species other than the standard test organism are considerably more sensitive. Different species and endpoints were included in case of data gaps.

The second concept, SUM RQ, is a simplified CA-based approach and is calculated by summing up the single substance RQs, i.e. the quotient of the measured environmental concentrations (MEC) and the assessment value (AV), of each sample:

$$
\mathrm{SUM} \mathrm{RQ}=\sum_{i=1}^{n} \mathrm{RQ}_{\mathrm{i}}=\sum_{i=1}^{n} \mathrm{MEC}_{i} / \mathrm{AF}_{i} .
$$

In the present study regulatory established environmental quality standards (EQS), e.g. from the WFD or related national legislation on water quality, were used as assessment values. In the absence of EQS or if new ecotoxicological data have recently been published, assessment values were derived from validated ecotoxicological data, i.e. PNEC, EQS proposals or threshold values for national monitoring programs.

All ecotoxicological data were collected from online databases (e.g. UBA ETOX [28], US EPA ECOTOX [29], ECHA information on chemicals [30] or Pesticides Properties DataBase [31]), regulatory risk assessments from EU and national institutions or scientific publications. Data were last updated prior the evaluations in 08/2018 (acute toxicity) and 01/2019 (chronic toxicity). Since EQS and PNEC values have already been derived considering AF, no further factors were used to calculate the SUM $R Q$. Mixture risks calculated by $R Q_{\text {mix }}$ and $S U M R Q$ were compared to RQs of single-substance evaluations. Environmental risks were considered as low when RQs were less than 1.

\section{Drivers of mixture toxicity}

Substances relevant for the mixture risks were identified by calculating the $\mathrm{P}_{90}$ value according to Ginebreda et al. [32, 33]. The $\mathrm{P}_{90}$ value describes the number of substances accounting for $90 \%$ of the SUM TU. Relevant substances were ranked according to their percentage (\%TU) of the total mixture toxicity. Substances frequently showing high \%TUs were considered as drivers of mixture toxicity.

\section{Implications of the monitoring design for mixture risk assessments}

To assess the influence of the monitoring design, data collected at the sampling site Eppinghoven during the WFD surveillance monitoring of LANUV were analysed for mixture effects using the methods described above. At the same time, the applicability of the mixture risk assessment approaches to WFD surveillance monitoring data is examined.

Analytical methods used for the surveillance monitoring are presented in Additional file 1: Table S2-1. This sampling site is located in between two sites of the monitoring program by the Erftverband. In 2016/2017, 15 samplings were performed at Eppinghoven. Five datasets with sampling dates matching the dates of the Erftverband monitoring program were selected for mixture evaluation. These samples were taken in May, late June, August, early November 2016 and January 2017, representing two dry and three wet conditions. In contrast to the Erftverband, the number of substances analysed varied between two and eight for most of the samplings. In November, a broader set of 58 substances were evaluated as part of the annual WFD surveillance monitoring.

\section{Results and discussion}

\section{Available ecotoxicological data}

Assessment values could be found for $84 \%$ of the detected substances. The remaining $16 \%$ mainly consisted of pesticide metabolites, pharmaceutical metabolites and selected pharmaceuticals, such as X-ray contrast agents, which are assumed to be of low ecotoxicological relevance (Additional file 1: Table S3 1-2). Available data for effect concentrations $\left(\mathrm{EC}_{\mathrm{x}} / \mathrm{NOEC}\right)$ showed considerably more data gaps. A complete set of toxicity data for algae, invertebrates and fish (aquatic base set) was found for 76\% (acute toxicity) and 54\% (chronic toxicity) of the substances. However, the availability of data varied for the biological groups as well as for the substance groups. In particular, there were large data gaps for macrophytes and fish, as well as for pharmaceuticals. 


\section{Single-substance evaluation}

In total, 98 of 153 analysed substances were detected, consisting of 55 pesticides, 31 pharmaceuticals and 12 other substances (Additional file 1: Table S1 1-3). An exceedance of the assessment value $(R Q \geq 1)$ was observed for 36 substances (26 pesticides, 6 pharmaceuticals and 4 other substances). Overall, there were 923 AV exceedances during the sampling campaign. Pharmaceuticals accounted for $79 \%$ of the exceedances, pesticides for $15 \%$ and other substances for $7 \%$. In $90 \%$ of the samples at least one substance was detected in concentrations above the AV. However, $80 \%$ of AV exceedances were caused by only three substances: diclofenac (47\%), ibuprofen (27\%), triclosan (5\%; Additional file 1: Table S4 1-2).

\section{Mixture evaluation}

Acute mixture risks were calculated for $32 \%$ of samples $\left(\mathrm{RQ}_{\text {mix,acute }} \geq 1\right)$ with most $\mathrm{RQs}$ ranging between 1 and 10 (Fig. 2). In contrast, chronic mixture RQs were $\geq 1$ in $60 \%\left(\mathrm{RQ}_{\mathrm{mix}, 1000}\right), 90 \%\left(\mathrm{RQ}_{\mathrm{mix}, 10}\right)$ and $91 \%$ (SUM RQ) of the samples, respectively (Fig. 2). The SUM RQ and $\mathrm{RQ}_{\text {mix,10 }}$ based on chronic toxicity data followed similar patterns of mixture risks with most mixture RQs ranging between 1 and 100 . In contrast, the $R Q_{\text {mix,1000 }}$ showed a wider variability with most RQs between 0.1 and $\geq 100$. Also, the $R_{\text {mix }, 1000}$ had maximum RQs up to 2588, whereas $R_{\text {mix }, 10}$ and SUM RQ showed RQs up to 100 and 509, respectively. However, continuously greater peak $\mathrm{RQ}_{\text {mix }, 1000}$ during the entire sampling campaign are likely to be caused by the application of the safety factor of 1000 on acute data.

Often environmental risks were not only predicted by mixture evaluations but also by single-substance evaluations. Specifically, mixture $R Q s \geq 1$ without any substances exceeding the individual AV were only calculated for $0.4 \%\left(\mathrm{RQ}_{\text {mix,acute }}\right), 1.0 \%\left(\mathrm{RQ}_{\text {mix,1000 }}\right), 0.0 \%\left(\mathrm{RQ}_{\text {mix,10 }}\right)$ and $0.8 \%$ (SUM RQ) of the samples. However, compared to single-substance evaluation calculated risks of both acute and chronic toxicity were generally greater when mixture effects were considered. Therefore, both mixture approaches assess environmental risks more conservatively than single-substance evaluations. Since several substances occur simultaneously in the environment, the mixture risk assessment also corresponds to a more realistic approach.

\section{Drivers of mixture toxicity}

Only a limited number of substances significantly contributed to the overall estimated mixture risks. In 93\% of the samples $\left(\mathrm{RQ}_{\text {mix,acute }}\right)$ as well as in $76 \%\left(\mathrm{RQ}_{\text {mix,1000 }}\right)$ and $80 \%\left(\mathrm{RQ}_{\mathrm{mix}, 10}\right)$ of the samples only one to three substances accounted for $90 \%$ of the SUM TU $\left(\mathrm{P}_{90}\right.$ value; Additional file 1: Table S5-1). This is consistent with previous studies reporting between one and eight substances as main drivers of mixture toxicity [3336]. These substances, however, can vary seasonally and regionally, which was also observed in this study. Therefore, even if only a few substances are the main contributors to the mixture toxicity, a high number

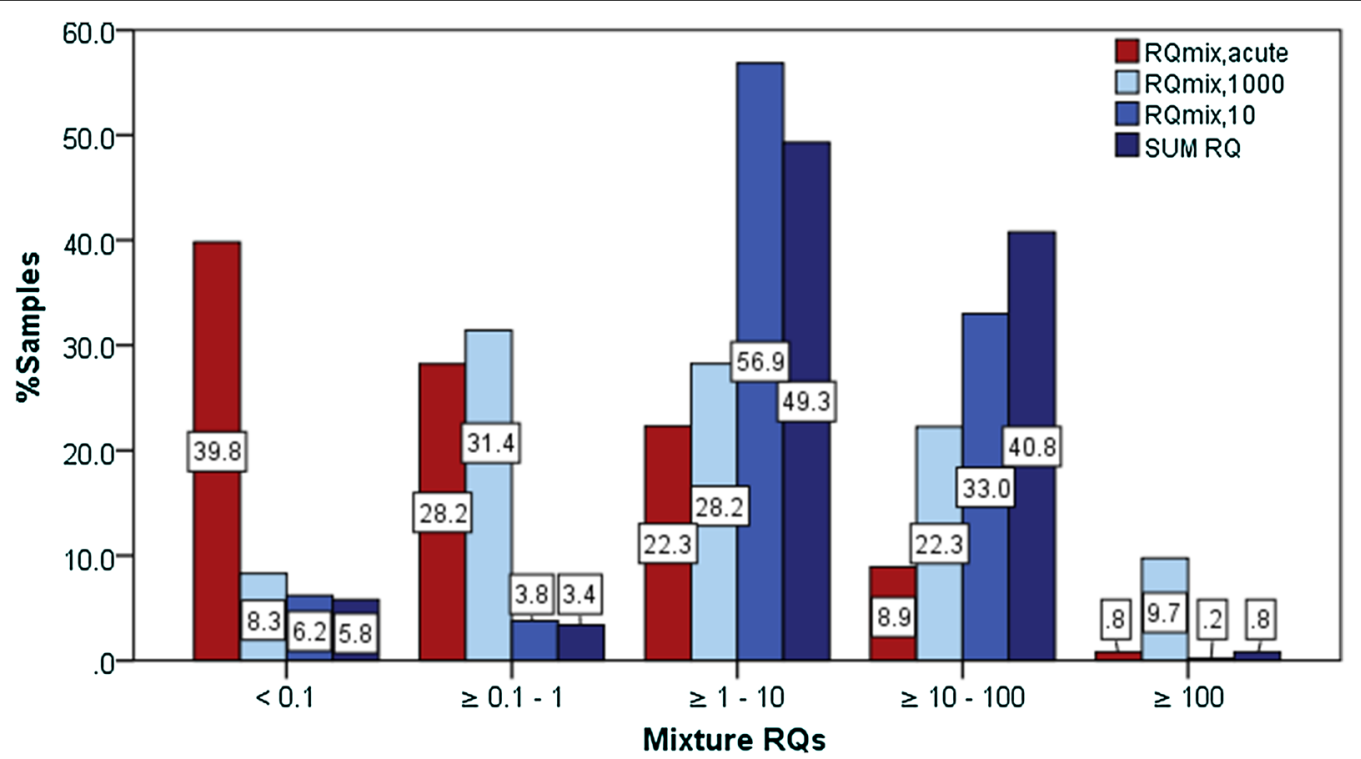

Fig. 2 Mixture risk quotients (RQ) in the Erft River sampling campaign 2016/2017. Acute (red) and chronic (blue) mixture risks are grouped according to the percentage of samples 
of substances need to be analysed in order to obtain a comprehensive overview of the mixture risks in surface waters [36, 37].

Substances relevant for the mixture risks were identified by calculating the (mean) \%TU. Important toxicity drivers with a high proportion of the total mixture risks are listed in detail in Additional file 1: Table S5-2. The toxicity drivers as well as the predicted mixture toxicity differed distinctly between the biological groups.

For algae and macrophytes acute mixture risks were calculated for $25 \%$ and $23 \%$ of the samples, respectively (Additional file 1: Table S5-3). Main drivers of the acute mixture toxicity for the aquatic flora were different herbicides as well as fungicides, the preservative triclosan and the antibiotic clarithromycin. On average $75 \%$ and 96\% of the SUM TU for algae and macrophytes were attributed to pesticides (Additional file 1: Table S5-5). In accordance with these results, chronic mixture risks based on acute toxicity data were primarily observed for algae and macrophytes with a SUM TU $\geq 0.001$ in $45 \%$ and 55\% of the samples (Additional file 1: Table S5-3). Chronic mixture risks based on chronic toxicity data (SUM TU $\geq 0.1$ ) were calculated for $21 \%$ and $14 \%$ of the samples for algae and macrophytes, respectively (Additional file 1: Table S5-4). Main drivers of the chronic mixture toxicity for the aquatic flora were again different herbicides as well as fungicides, the preservative triclosan and the antibiotics clarithromycin and sulfamethoxazole. This is consistent with previous studies, which also found high pesticide risks particularly caused by herbicides, which were frequently detected in surface waters across Europe [35, 38-43].

No acute mixture risks were predicted for fish (Additional file 1: Table S5-3). However, chronic mixture risks were highest for this biological group with risks calculated for $90 \%$ of the samples (Additional file 1: Table S5-4). Main drivers of toxicity for fish were diclofenac and ibuprofen. Diclofenac is commonly detected at relevant concentrations in surface waters in NRW and across the globe [44, 45]. Munz et al. [35] described a reduction of the mixture toxicity by more than $60 \%$ when removing the main drivers diclofenac, diazinon and clothianidin from the dataset. In the present study, a simulated reduction of diclofenac by $20 \%$, $80 \%$ and $100 \%$ lowered calculated chronic mixture risks by up to $14 \%, 52 \%$ and $61 \%$, respectively (Additional file 1: Table S5-6). Therefore, diclofenac has a particular influence on chronic mixture risk for fish in the Erft River. Since chronic effects of diclofenac were not captured by the $\mathrm{RQ}_{\text {mix,1000 }}$ using acute toxicity data only, chronic risks were predicted for only $17 \%$ of samples by this approach.
Mixture risks calculated for aquatic invertebrates were lower and less frequently detected in the present study, with acute risks observed for $0.6 \%\left(\mathrm{RQ}_{\text {mix,acute }}\right)$ of the samples (Additional file 1: Table S5-3) as well as chronic risks observed for $34 \%\left(\mathrm{RQ}_{\text {mix,1000 }}\right)$ and $4 \%\left(\mathrm{RQ}_{\text {mix }, 10}\right)$ of the samples, respectively (Additional file 1: Table S5-4). Important drivers included insecticides (dichlorvos and diazinon), industrial chemicals (HHCB, benzotriazole) and pharmaceuticals (carbamazepine and clarithromycin). However, mixture risks for aquatic invertebrates might be underestimated since only three insecticides, diazinon, dichlorvos and imidacloprid, were measured during the sampling campaign in the Erft River. Insecticides have a particularly high toxicity towards aquatic invertebrates, though [41]. Furthermore, interspecies differences in sensitivity can impair the environmental risk assessment of chemicals. Standard test species, e.g. Daphnia magna for aquatic invertebrates, do not always cover the most sensitive species in the environment [46, 47].

The contribution of different substance groups to the SUM TUs of algae, invertebrates and fish is shown for a rain event sampling in early June 2016 in Fig. 3, which demonstrates general patterns of the mixture risks and the contributing drivers of mixture toxicity for the biological groups as described above. Due to the pesticide run-off, high mixture risks were detected for algae based on the acute toxicity data. Despite dilution effects chronic risks due to diclofenac and ibuprofen remained highest for fish. Persistent mixture risks were found both for the aquatic flora (acute and chronic mixture risks) and for fish (chronic mixture risk). This demonstrates that there is a concern for long-term mixture effects on the aquatic organisms in the Erft River even though the chronic mixture risk assessment was done for single sampling events in this study. However, the choice of acute or chronic toxicity data as basis for the chronic mixture risk assessment had a distinct impact on the calculated mixture risks and identified drivers of mixture toxicity. Thus, differences between $\mathrm{RQ}_{\text {mix,1000 }}$ and $\mathrm{RQ}_{\text {mix,10 }}$ were more pronounced than between $\mathrm{RQ}_{\mathrm{mix}, 10}$ and SUM RQ.

Evaluations of drivers of mixture toxicity using the SUM RQ (mean \%RQ) led to similar results as the TU approach (Additional file 1: Table S5-7). Main drivers were diclofenac, ibuprofen and triclosan as well as different pesticides including isoproturon, terbuthylazine, dimethenamid, nicosulfuron and fenpropidin.

\section{Seasonal and spatial variation}

Seasonal and spatial variations of mixture RQs in the Erft River are shown in Fig. 4 and Additional file 1: Table S6-1. Calculated mixture risks increased distinctly downstream of the first two WWTP discharges $(\mathrm{km} 84$ and $\mathrm{km}$ 

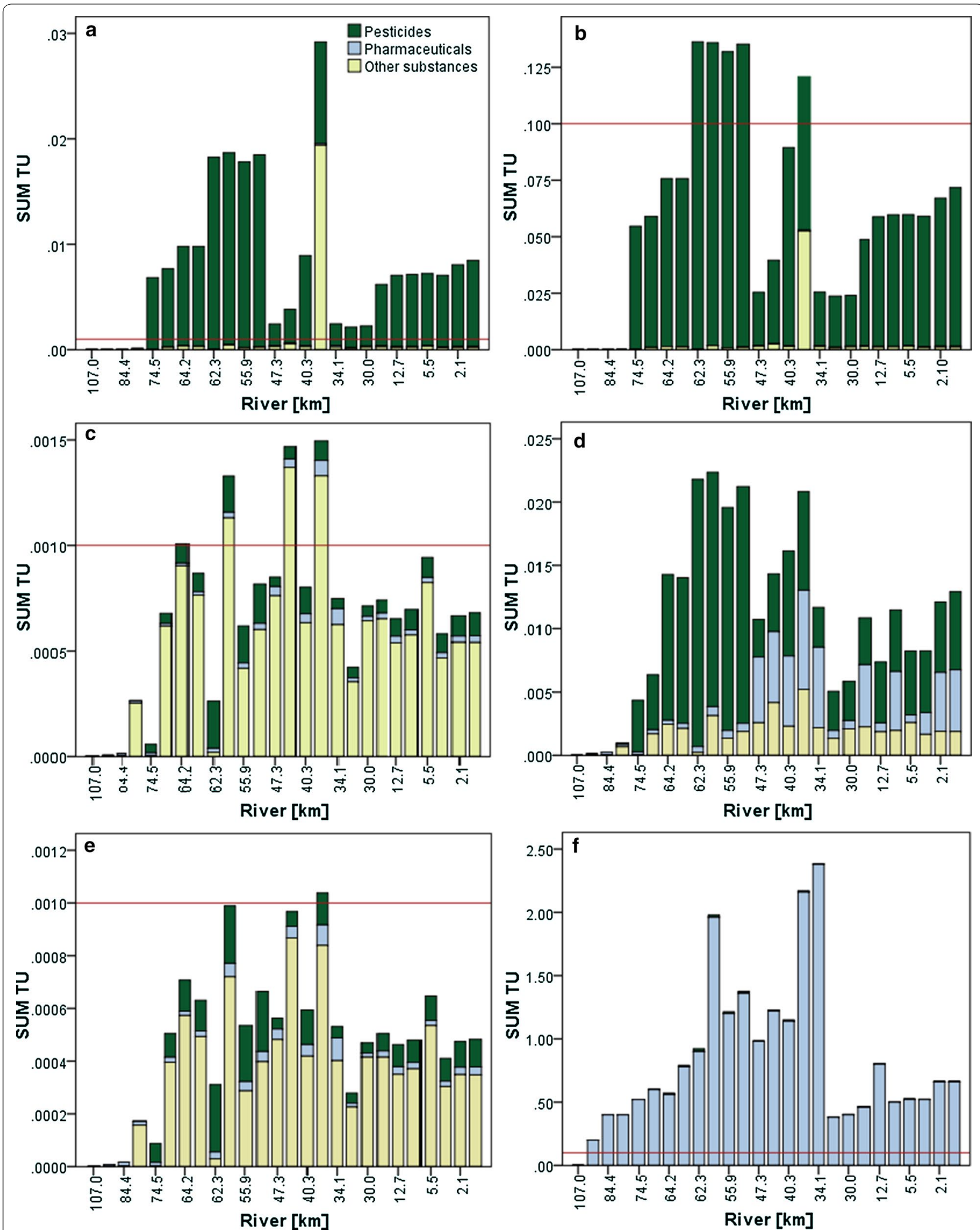

Fig. 3 Contribution of different substance groups to the SUM TU in early June 2016. Chronic SUM TUs of pesticides, pharmaceuticals and other substances along the Erft River during a rain event sampling in June 2016 are shown for algae (a, b), aquatic invertebrates (c, d), and fish (e, $\mathbf{f})$ based on acute $(\mathbf{a}, \mathbf{c}, \mathbf{e})$ and chronic ( $\mathbf{b}, \mathbf{d}, \mathbf{f})$ toxicity data. Red lines indicate risk thresholds of 0.001 and 0.1 , respectively 


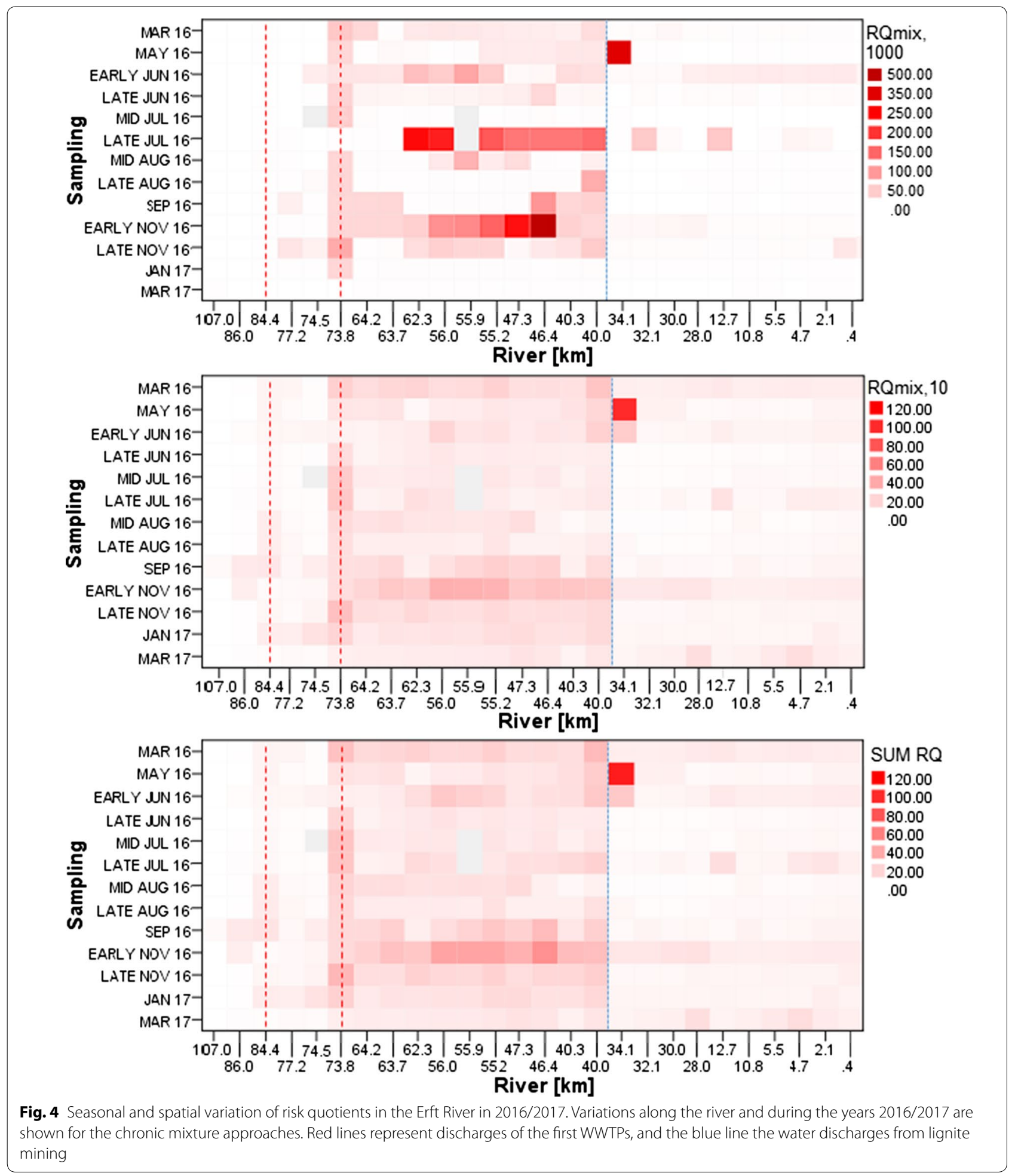

74). A clear decrease occurred due to diluting effects of water discharges from lignite mining between $\mathrm{km} 40$ and $\mathrm{km}$ 34. In May 2016, a one-time detection of the organophosphate insecticide dichlorvos in a concentration of
$0.06 \mu \mathrm{g} / \mathrm{L}$ led to a high acute and chronic environmental risk at $\mathrm{km} \mathrm{34}$. Dichlorvos was banned in the EU in 2012 [48], and the source of this contamination could not be identified. In general, monthly variations of the 
$R Q_{\text {mix,acute }}$ and $R Q_{\text {mix,1000 }}$ based on acute toxicity data are the results of the input of different pesticides with varying concentrations. Highest $\mathrm{RQ}_{\text {mix,acute }}$ and $\mathrm{RQ}_{\text {mix,1000 }}$ were calculated for May, early June, late July and early November. Both the SUM RQ and the $R_{\text {mix,10 }}$ based on chronic toxicity data showed less seasonal and spatial variations, since the main drivers, e.g. diclofenac and ibuprofen, were continuously detected throughout the year. Only minor seasonal differences were observed with lower pharmaceutical concentrations in summer. This might have resulted from a greater degradation of substances in the WWTP due to high temperatures or lower consumption of some pharmaceuticals during the summer season $[49,50]$.

A clear influence of weather conditions on mixture RQs could not be observed. Peak RQs, mainly for $R_{\text {mix,1000, }}$ were detected both during rainy and dry weather conditions. As expected, high $\mathrm{RQ}_{\text {mix,acute }}$ and $\mathrm{RQ}_{\text {mix,1000 }}$ were observed after rain events (early June and November) due to pesticide run-off, which is in agreement with previous studies $[40,51]$. However, high $\mathrm{RQ}_{\text {mix,acute }}$ and $\mathrm{RQ}_{\text {mix,1000 }}$ were also detected during dry periods (e.g. late July). During these periods, main toxicity drivers included triclosan, sulfamethoxazole, isoproturon, terbuthylazine and diuron. The herbicides have previously been reported to originate from WWTP effluents [35, 52-54]. The impact of WWTP discharges on the pesticide load is particularly relevant during dry periods, since other inputs of diffuse sources as well as dilution effects in the surface water are limited in dry periods and under low flow conditions.

Although pesticide concentrations varied throughout the year, pesticide mixtures exert a relatively continuous toxic pressure, especially on the aquatic flora. The variation of the SUM TU $\mathrm{T}_{\text {Algae }}$ of 18 herbicides during the sampling campaign in 2016/2017 is shown for the Erft tributary Swist in Fig. 5. Acute mixture risks (SUM $\mathrm{TU} \geq 0.01$ ) were predicted for 6 of 12 sampling events in the Swist, which were distributed over the entire sampling period. As grab samplings only capture a "snapshot" [55] of pesticide concentrations at the time of sampling likely underestimating the actual pesticide exposure $[40,56,57]$, a continuing toxic pressure leading to limited recovery times can be expected in the Swist. This observation agrees with previous findings of a continuous pressure on aquatic organisms due to pesticide contaminations [56, 58]. Mixture risk assessments including exposure data of different pesticides enable the detection of persisting effects of varying pesticides throughout the seasons. Thus, pesticide risks in the environment can be more adequately described by mixture risk assessment rather than by single-substance risk evaluations, which disregard additive effects and temporal variations of different pesticides during the year.

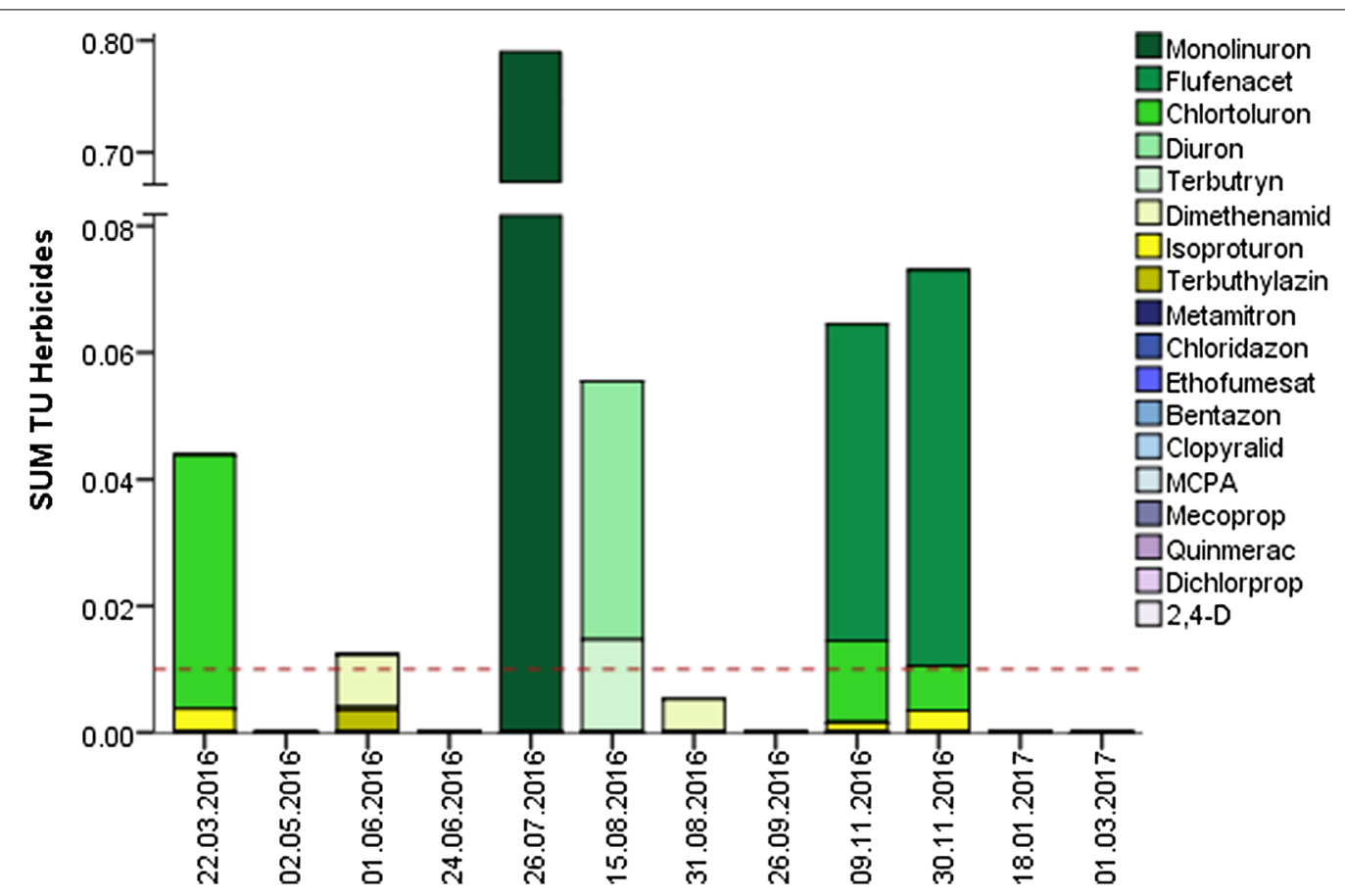

Fig. 5 Mixture toxicity of different herbicides in the Erft tributary Swist in 2016/2017. The SUM TU of 18 herbicides calculated based on the acute toxicity data is shown for algae. Red line indicates the threshold of potential acute mixture risks (SUMTU acute $\geq 0.01$ ) 


\section{Implication of the monitoring design for mixture risk assessments}

To assess the influences of the monitoring design, calculated mixture risks were compared for two datasets from the LANUV and the Erftverband. Whilst the Erftverband performed an extensive monitoring program in the Erft River in 2016/2017, data from the LANUV originated from the routine WFD surveillance monitoring program at the monitoring site Eppinghoven. In contrast to the Erftverband, the number of substances analysed by the LANUV differed between the sampling events. In total, 58 substances were detected at the sampling site of Eppinghoven, varying between 2 and 52 detected substances per sampling. The Erftverband found 39 substances (between 18 and 26 substances per sampling) at the two sampling sites closest to Eppinghoven. Chronic mixture risks $\left(\mathrm{RQ}_{\mathrm{mix}, 1000}\right.$ and $\left.\mathrm{RQ}_{\text {mix,10}}\right)$ calculated for both datasets are shown in Fig. 6 and Additional file 1: Table S7-1. In March and November 2016, the $R_{\text {mix,1000 }}$ at the sampling site Eppinghoven was approximately tenfold higher than the $\mathrm{RQ}_{\mathrm{mix}, 1000}$ at the surrounding sites from the Erftverband. This was caused by the effect of the polycyclic aromatic hydrocarbons (PAH), fluoranthene and benzo[a]pyrene, which were not included in the monitoring program of the Erftverband. However, the environmental risk assessment for this substance group is particularly difficult since PAH are strongly hydrophobic and therefore often only partly bioavailable. The LANUV measured only total PAH concentrations, not the dissolved fraction. Therefore, the risk assessment of
PAH in the Erft River depicts only a rough estimation of potential mixture effects of this group. In addition to this, there was a different limit of quantification for clarithromycin $(0.2 \mu \mathrm{g} / \mathrm{L}$ vs. $0.025 \mu \mathrm{g} / \mathrm{L})$ resulting in a more frequent quantification of this substance by the LANUV at Eppinghoven. In contrast to this, calculated $\mathrm{RQ}_{\text {mix,10 }}$ of both sampling sites from the Erftverband were 4- to 200fold higher compared to Eppinghoven with the exception of November 2016. This exception was mainly caused by a continuous monitoring of diclofenac by the Erftverband whereas this substance was only measured by LANUV in November. Generally, the comparison demonstrates that datasets comprising only a few substance groups are of limited value for mixture risk assessments. This limitation has to be taken into account when differently composed datasets are compared.

Comparing mixture risk assessments based on two different datasets demonstrates the considerable influence of the monitoring design on the results of mixture risk assessments. This includes the selection of substances monitored, timing and frequency of samplings and the analytical methods used. When important toxicity drivers are not monitored, the calculated mixture risk is likely to underestimate the chemical stress. Both datasets lack data on further substance groups, such as metals which are likely to be present in discharges from lignite mining, or insecticides with a high toxicity towards aquatic invertebrates. Moreover, the use of grab water samples can lead to an underestimation of peak concentrations of, e.g. pesticide concentrations after rain events $[40,56,57]$.
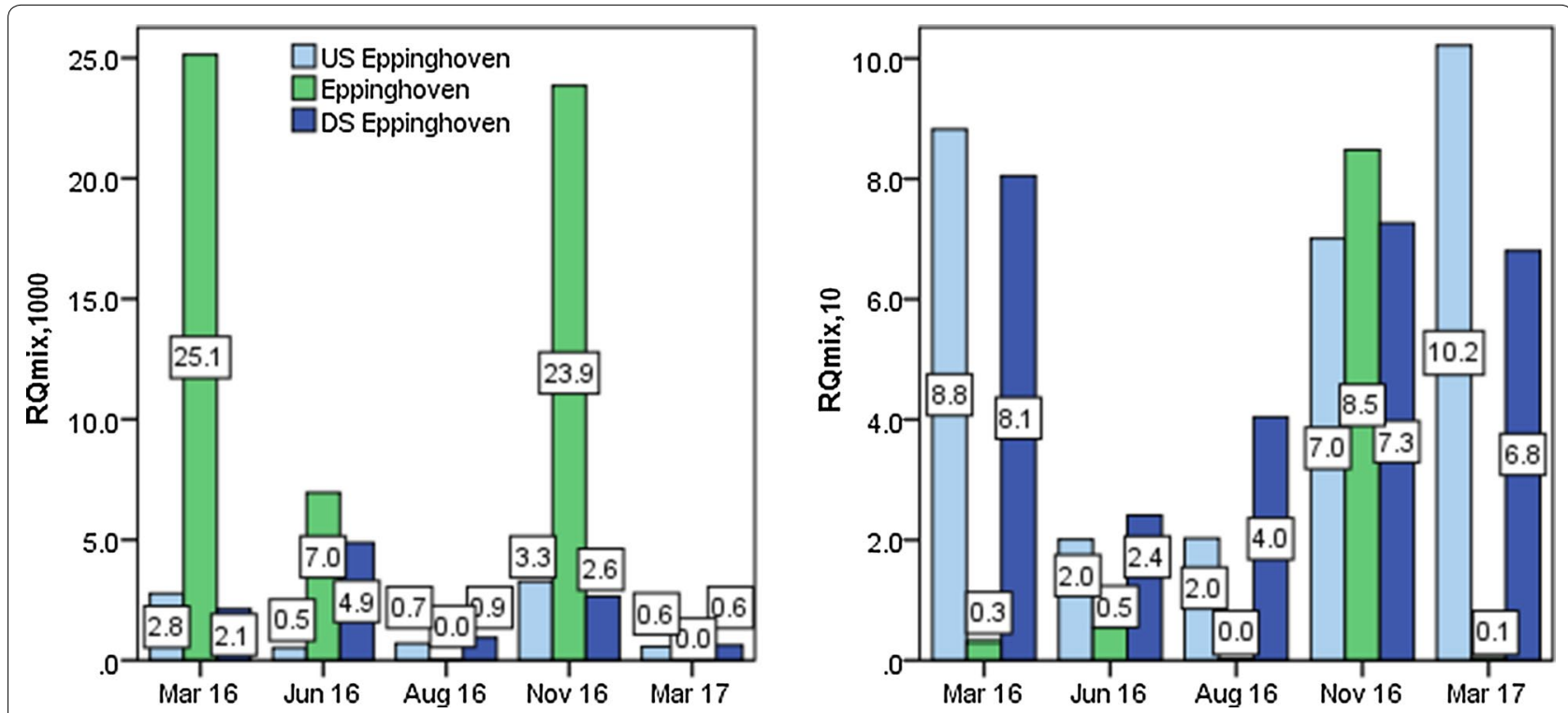

Fig. 6 Mixture risk quotients for two monitoring datasets from the Erft River. $R Q_{\text {mix, } 1000}$ and $R Q_{\text {mix, } 10}$ were calculated for data on adjacent sampling sites from the LANUV (Eppinghoven) and Erftverband (upstream (US) and downstream (DS) of Eppinghoven) for parallel sampling dates in 2016/2017 
Frequent grab samplings as well as additional composite samplings are therefore recommended for realistic mixture risk assessments [40, 41, 56, 57]. Additional bioanalytical monitoring, so called effect-based methods (EBM), can improve the risk assessments of chemical pollution, as well. These methods are able to capture the effects of unmonitored, unknown or undetected substances, e.g. if their concentrations are below the technical limit of quantification, as well as the effects of complex chemical mixtures. Risks of underestimating mixture effects due to data gaps in exposure and toxicity data could be reduced using additional EBM $[42,59,60]$.

\section{Applicability of mixture risk assessments}

Both mixture approaches used in this study can be applied to data of the WFD monitoring. Since the SUM RQ was proven to be a simple but conservative approach for mixture assessment, it can be applied as a first-tier approach. The SUM RQ can easily be calculated based on available toxicity data without the need for detailed research on effect concentrations. Underlying assessment values include both acute and chronic endpoints as well as effect concentrations of the most sensitive species. Thus, the chance of underestimating mixture risks due to data gaps and differences in species sensitivity is lower for the SUM RQ than for the $R Q_{\text {mix }}$. If the SUM RQ indicates potential risks, a detailed risk evaluation can be performed using the acute and chronic $\mathrm{RQ}_{\text {mix }}[10$, 61]. However, since calculated mixture risks and identified drivers varied between $R Q_{\text {mix,1000 }}$ and $R Q_{\text {mix,10, }}$, chronic mixture risks are recommended to be based on chronic toxicity data-whenever enough data are available-additionally to the established calculations based on acute data. The application of the TU approach can be facilitated by improving the accessibility and exchange of high-quality ecotoxicological data, e.g. by establishing consistent long-term database(s) for ecotoxicological information on chemicals of different substance classes $[61,62]$. Considering the additional time resources needed, mixture risk assessments are recommended for large datasets, e.g. at surveillance monitoring sites or from extensive investigative monitoring and other targeted special measurement programs. Mixture risk evaluations of small monitoring datasets provide only limited information on the actual mixture risks to aquatic organisms and would have little relevance for the evaluation of the water quality. To compare mixture risk assessments, e.g. comparing different sampling sites or evaluating the development of the water quality over time, consistent and comparable monitoring strategies including defined sets of substances analysed are required.

\section{Conclusion}

The biocoenosis of the Erft River and its tributaries is subjected to pronounced effects by a large number of chemical substances and varying substance mixtures throughout the year. On the one hand, continuous contamination by alternating pesticides might lead to persisting mixture risks for the aquatic flora, whilst on the other hand a continuous release of pharmaceuticals from WWTPs poses a chronic risk to fish. Furthermore, insecticides and industrial chemicals (e.g. HHCB and benzotriazole) were observed to exert acute pressures on aquatic invertebrates. Overall, only a limited number of substances significantly contributed to the mixture risks in each sample. However, these substances varied seasonally and regionally during the present study.

Both CA-based mixture approaches discussed in this paper can be used for a conservative assessment of mixture risks based on the available monitoring data. As opposed to single-substance evaluations, additive effects of different mixture components are considered even when each substance occurs in concentrations below the individual PNEC or EQS. Furthermore, mixture risks can be assessed for an extended time period and therefore can reveal recurring toxic pressures for certain biological groups. Analysis of drivers of mixture toxicity may guide mitigation measures and water management plans. All in all, risk assessments of chemical mixtures characterise the aquatic contamination more realistically than singlesubstance assessments.

For the integration of mixture risk evaluations into the assessment and management of chemical water quality, a two-staged assessment combining both approaches is suggested. A simple but conservative evaluation of mixture risks based on SUM RQ can be followed by a detailed evaluation using $R Q_{\text {mix }}$, if preliminary results indicate pronounced mixture risks. Since the choice of acute or chronic toxicity data for mixture risk assessments had a distinct impact on the calculated mixture risks and identified drivers, mixture risk assessment is recommended to be based on not only the commonly applied acute toxicity data but also on chronic toxicity data.

Data gaps of both ecotoxicological and exposure data can lead to uncertainties in the mixture risk assessment. Therefore, sampling design and sampling methods need to be considered when evaluating mixture risks. Whilst mixture risk assessments may provide information on toxic pressures for a given water body, they can only be compared with other mixture risk assessments when consistent and comparable sampling designs are used. To improve future risk assessments, the accessibility and exchange of high-quality ecotoxicological data should be enhanced. 


\section{Supplementary information}

Supplementary information accompanies this paper at https://doi. org/10.1186/s12302-020-00326-5.

Additional file 1. Additional tables.

\section{Abbreviations}

AF: Assessment factor; AV: Assessment value; CA: Concentration addition; EBM: Effect-based methods; ECx: Effect concentration; EQS: Environmental quality standard; GC-MS/MS: Gas chromatography coupled with tandem mass spectrometry; IA: Independent action; LANUV: North Rhine Westphalian State Agency for Nature, Environment and Consumer Protection; HPLC-MS/ MS: High-performance liquid chromatography coupled with tandem mass spectrometry; MEC: Measured environmental concentration; MoA: Mode of action; MULNV: Ministry for Environment, Agriculture, Conservation and Consumer Protection of the State of North Rhine Westphalia; NRW: North Rhine Westphalia; PAH: Polycyclic aromatic hydrocarbons; PNEC: Predicted no effect concentration; RQ: Risk quotient; SUM TU: Sum of toxic units; TU: Toxic unit; WFD: Water framework directive; WWTP: Wastewater treatment plant.

\section{Acknowledgements}

Not applicable.

\section{Authors' contributions}

NM compiled and analyzed the data and drafted the manuscript. BG coordinated the study. SR compiled ecotoxicological data and ERA approaches. MT supervised the sampling campaign in the Erft River. All authors read and approved the final manuscript.

\section{Funding}

The project was funded by the Ministry for Environment, Agriculture, Conservation and Consumer Protection of the State of North Rhine Westphalia (MULNV).

\section{Availability of data and materials}

Data generated and analysed during this study are included in this article and its additional files. Complete raw data as well as ecotoxicological data basis are available from the corresponding author on reasonable request.

\section{Ethics approval and consent to participate}

The manuscript does not report on or involve the use of any animal or human data or tissue.

\section{Consent for publication}

Not applicable.

\section{Competing interests}

The authors declare that they have no competing interests.

\section{Author details}

${ }^{1}$ LANUV NRW, Wallneyer Str. 6, 45133 Essen, Germany. ${ }^{2}$ Erftverband, Am

Erftverband 6, 50126 Bergheim, Germany.

Received: 10 December 2019 Accepted: 8 March 2020

Published online: 30 March 2020

\section{References}

1. ATSDR (2004) Guidance manual for the assessment of joint toxic action of chemical mixtures. ATSDR, Atlanta

2. Kienzler A, Bopp S, van der Linden S, Berggren E, Worth A (2016) Regulatory assessment of chemical mixtures: requirements, current approaches and future perspectives. Regul Toxicol Pharmacol 80:321-334. https://doi. org/10.1016/j.yrtph.2016.05.020

3. Silva E, Rajapakse N, Kortenkamp A (2002) Something from "nothing" eight weak estrogenic chemicals combined at concentrations below NOECs produce significant mixture effects. Environ Sci Technol. https:// doi.org/10.1021/es0101227
4. European Commission (2012) COMMUNICATION FROM THE COMMISSIONTO THE COUNCIL: the combination effects of chemicals-chemical mixtures, COM(2012) 252 final. Brussels

5. Kortenkamp A, Faust M (2018) Regulate to reduce chemical mixture risk. Science 361:224-226. https://doi.org/10.1126/science.aat9219

6. European Environment Agency (EEA) (2018) Chemicals in European waters: knowledge developments. Publications Office of the European Union, Luxembourg

7. Altenburger R, Ait-Aissa S, Antczak P, Backhaus T, Barceló D, Seiler T-B et al (2015) Future water quality monitoring — adapting tools to deal with mixtures of pollutants in water resource management. Sci Total Environ 512-513:540-551. https://doi.org/10.1016/j.scitotenv.2014.12.057

8. Carvalho RN, Arukwe A, Ait-Aissa S, Bado-Nilles A, Balzamo S, Baun A et al (2014) Mixtures of chemical pollutants at European legislation safety concentrations: how safe are they? Toxicol Sci 141:218-233. https://doi. org/10.1093/toxsci/kfu118

9. Kortenkamp A, Faust M, Backhaus T, Altenburger R, Scholze M, Müller C et al (2019) Mixture risks threaten water quality: the European Collaborative Project SOLUTIONS recommends changes to the WFD and better coordination across all pieces of European chemicals legislation to improve protection from exposure of the aquatic environment to multiple pollutants. Environ Sci Eur 31:69. https://doi.org/10.1186/s1230 2-019-0245-6

10. Backhaus T, Faust M (2012) Predictive environmental risk assessment of chemical mixtures: a conceptual framework. Environ Sci Technol 46:2564-2573. https://doi.org/10.1021/es2034125

11. Kortenkamp A, Backhaus T, Faust M (2009) State of the art report on mixture toxicity: contract, 70307

12. Loewe S, Muischnek H (1926) Über Kombinationswirkungen. NaunynSchmiedeberg's Arch Pharmacol 114:313-326

13. Bliss Cl (1939) The toxicity of poisons applied jointly. Ann Appl Biol 26:585-615

14. Faust M, Altenburger R, Backhaus T, Blanck H, Boedeker W, Gramatica $P$ et al (2001) Predicting the joint algal toxicity of multi-component s-triazine mixtures at low-effect concentrations of individual toxicants. Aquat Toxicol 56:13-32. https://doi.org/10.1016/S0166-445X(01)00187-4

15. Altenburger R, Boedeker W, Faust M, Grimme LH (1996) Regulations for combined effects of pollutants: consequences from risk assessment in aquatic toxicology. Food Chem Toxicol 34:1155-1157. https://doi. org/10.1016/S0278-6915(97)00088-4

16. Belden JB, Gilliom RJ, Lydy MJ (2007) How well can we predict the toxicity of pesticide mixtures to aquatic life? Integr Environ Assess Manag 3:364-372

17. Boedeker W, Drescher K, Altenburger R, Faust M, Grimme LH (1993) Combined effects of toxicants: the need and soundness of assessment approaches in ecotoxicology. Sci Total Environ 134:931-939

18. Faust M, Altenburger R, Boedeker W, Grimme LH (1996) Kombinationswirkungen von Schadstoffen in Gewässern: vorhersagbarkeit und Beurteilung. Impulse aus der Forschung Nr 21:36-40

19. Cedergreen N (2014) Quantifying synergy: a systematic review of mixture toxicity studies within environmental toxicology. PLoS ONE 9:e96580. https://doi.org/10.1371/journal.pone.0096580

20. Faust M, Altenburger R, Backhaus T, Blanck H, Boedeker W, Gramatica P et al (2003) Joint algal toxicity of 16 dissimilarly acting chemicals is predictable by the concept of independent action. Aquat Toxicol 63:43-63. https://doi.org/10.1016/S0166-445X(02)00133-9

21. Junghans M, Backhaus T, Faust M, Scholze M, Grimme LH (2006) Application and validation of approaches for the predictive hazard assessment of realistic pesticide mixtures. Aquat Toxicol 76:93-110

22. MULNV (2015) Steckbriefe der Planungseinheiten in den nordrhein-westfälischen Anteilen von Rhein, Weser, Ems und Maas - Bewirtschaftungsplan 2016-2021: Oberflächengewässer und Grundwasser Teileinzugsgebiet Rhein/Wupper. Düsseldorf

23. Erftverband (2018) ABSCHLUSSBERICHT Mikroschadstoffe in der Erft: Bilanzierung/Modellierung. Konzepte zur Reduzierung, Bergheim

24. Erftverband (2018) Jahresbericht 2018: Wasserwirtschaft für unsere Region

25. Coors A, Vollmar P, Sacher F, Polleichtner C, Hassold E, Gildemeister D, Kühnen U (2018) Prospective environmental risk assessment of mixtures in wastewater treatment plant effluents-theoretical considerations and 
experimental verification. Water Res 140:56-66. https://doi.org/10.1016/j. watres.2018.04.031

26. Watanabe H, Tamura I, Abe R, Takanobu H, Nakamura A, Suzuki T et al (2016) Chronic toxicity of an environmentally relevant mixture of pharmaceuticals to three aquatic organisms (alga, daphnid, and fish). Environ Toxicol Chem 35:996-1006. https://doi.org/10.1002/etc.3285

27. European Commission (2018) Technical guidance for deriving environmental quality standards (TGD EQS), Guidance Document No. 27

28. UBA ETOX — Informationssystem Ökotoxikologie und Umweltqualitätsziele. https://webetox.uba.de/webETOX. Accessed 12 Dec 2019

29. US EPA ECOTOX-ECOTOXicology Knowledgebase System. http://cfpub .epa.gov/ecotox/. Accessed 12 Dec 2019

30. ECHA Information on chemicals. https://echa.europa.eu/de/informatio n-on-chemicals. Accessed 12 Dec 2019

31. Lewis KA, Tzilivakis J, Warner D, Green A (2016) An international database for pesticide risk assessments and management. Hum Ecol Risk Assess 22:1050-1064. https://doi.org/10.1080/10807039.2015.1133242

32. Ginebreda A, Jelić A, Petrović M, López de Alda M, Barceló D (2012) New indexes for compound prioritization and complexity quantification on environmental monitoring inventories. Environ Sci Pollut R 19:958-970. https://doi.org/10.1007/s11356-011-0557-6

33. Ginebreda A, Kuzmanovic M, Guasch H, de Alda ML, Lopez-Doval JC, Munoz I et al (2014) Assessment of multi-chemical pollution in aquatic ecosystems using toxic units: compound prioritization, mixture characterization and relationships with biological descriptors. Sci Total Environ 468-469:715-723. https://doi.org/10.1016/j.scitotenv.2013.08.086

34. Price PS, Han X (2011) Maximum cumulative ratio (MCR) as a tool for assessing the value of performing a cumulative risk assessment. Int J Environ Res Public Health 8:2212-2225. https://doi.org/10.3390/ijerph8062212

35. Munz NA, Burdon FJ, de Zwart D, Junghans M, Melo L, Reyes M et al (2017) Pesticides drive risk of micropollutants in wastewater-impacted streams during low flow conditions. Water Res 110:366-377. https://doi. org/10.1016/j.watres.2016.11.001

36. Gustavsson M, Kreuger J, Bundschuh M, Backhaus T (2017) Pesticide mixtures in the Swedish streams: environmental risks, contributions of individual compounds and consequences of single-substance oriented risk mitigation. Sci Total Environ 598:973-983. https://doi.org/10.1016/j. scitotenv.2017.04.122

37. Posthuma L, BrackW, van Gils J, Focks A, Müller C, de Zwart D, Birk S (2019) Mixtures of chemicals are important drivers of impacts on ecological status in European surface waters. Environ Sci Eur 31:71. https://doi. org/10.1186/s12302-019-0247-4

38. Casado J, Brigden K, Santillo D, Johnston P (2019) Screening of pesticides and veterinary drugs in small streams in the European Union by liquid chromatography high resolution mass spectrometry. Sci Total Environ 670:1204-1225. https://doi.org/10.1016/j.scitotenv.2019.03.207

39. Moschet C, Wittmer I, Simovic J, Junghans M, Piazzoli A, Singer H et al (2014) How a complete pesticide screening changes the assessment of surface water quality. Environ Sci Technol 48:5423-5432. https://doi. org/10.1021/es500371t

40. Spycher S, Mangold S, Doppler T, Junghans M, Wittmer I, Stamm C, Singer H (2018) Pesticide risks in small streams-how to get as close as possible to the stress imposed on aquatic organisms. Environ Sci Technol 52:4526-4535. https://doi.org/10.1021/acs.est.8b00077

41. Langer M, Junghans $M$, Spycher S, Koster M, Baumgartner C, Vermeissen E, Werner I (2017) Hohe Ökotoxikologische Risiken in Bächen. Aqua Gas 97:58-68

42. Junghans M, Langer M, Baumgartner C, Vermeirssen E, Werner I (2019) Ökotoxikologische Untersuchungen: Risiko von PSM bestätigt. Aqua Gas 26-34

43. Massei R, Busch W, Wolschke H, Schinkel L, Bitsch M, Schulze T et al (2018) Screening of pesticide and biocide patterns as risk drivers in sediments of major European river mouths: ubiquitous or river basin-specific contamination? Environ Sci Technol 52:2251-2260. https://doi.org/10.1021/acs. est.7b04355

44. BeekT aus der, Weber F-A, Bergmann A, Grüttner G, Carius A (2016) Pharmaceuticals in the environment: global occurrence and potential cooperative action under the Strategic Approach to International Chemicals Management (SAICM): Umweltbundesamt Texte 67/2016. Dessau

45. Hembrock-Heger A, Bergmann A (2007) Eintrag von Arzneimitteln und deren Verhalten und Verbleib in der Umwelt-Literaturstudie: LANUV Fachbericht 2. Recklinghausen
46. Wogram J, Liess M (2001) Rank ordering of macroinvertebrate species sensitivity to toxic compounds by comparison with that of Daphnia magna. Bull Environ Contam Toxicol 67:360-367

47. Von der Ohe PC, Liess M (2004) Relative sensitivity distribution of aquatic invertebrates to organic and metal compounds. Environ Toxicol Chem 23:150. https://doi.org/10.1897/02-577

48. European Commission (2012) Commission Decision of 10 May 2012 concerning the non-inclusion of dichlorvos for product type 18 in Annex I, IA or IB to Directive 98/8/EC of the European Parliament and of the Council concerning the placing of biocidal products on the market (notified under document C(2012) 3016): 2012/254/EU

49. Sari S, Ozdemir G, Yangin-Gomec C, Zengin GE, Topuz E, Aydin E et al (2014) Seasonal variation of diclofenac concentration and its relation with wastewater characteristics at two municipal wastewater treatment plants in Turkey. J Hazard Mater 272:155-164. https://doi.org/10.1016/j.jhazmat.2014.03.015

50. Vieno NM, Tuhkanen T, Kronberg L (2005) Seasonal variation in the occurrence of pharmaceuticals in effluents from a sewage treatment plant and in the recipient water. Environ Sci Technol 39:8220-8226. https://doi. org/10.1021/es051124k

51. Leu C, Singer H, Stamm C, Müller SR, Schwarzenbach RP (2004) Simultaneous assessment of sources, processes, and factors influencing herbicide losses to surface waters in a small agricultural catchment. Environ Sci Technol 38:3827-3834. https://doi.org/10.1021/es0499602

52. Fischer $P$ (1996) Quantifizierung der Eintragspfade für Pflanzenschutzmittel in Fließgewässer: Julius-Liebig-Universität Gießen

53. Gerecke A, Schärer M, Singer H, Müller S, Schwarzenbach R, Sägesser M et al (2002) Sources of pesticides in surface waters in Switzerland: pesticide load through waste water treatment plants-current situation and reduction potential. Chemosphere 48:307-315. https://doi.org/10.1016/ S0045-6535(02)00080-2

54. Wittmer IK, Bader H-P, Scheidegger R, Singer H, Lück A, Hanke I et al (2010) Significance of urban and agricultural land use for biocide and pesticide dynamics in surface waters. Water Res 44:2850-2862. https:// doi.org/10.1016/j.watres.2010.01.030

55. Allan IJ, Vrana B, Greenwood R, Mills GA, Roig B, Gonzalez C (2006) A "toolbox" for biological and chemical monitoring requirements for the European Union's Water Framework Directive. Talanta 69:302-322. https ://doi.org/10.1016/j.talanta.2005.09.043

56. Rabiet M, Margoum C, Gouy V, Carluer N, Coquery M (2010) Assessing pesticide concentrations and fluxes in the stream of a small vineyard catchment-effect of sampling frequency. Environ Pollut 158:737-748. https://doi.org/10.1016/j.envpol.2009.10.014

57. Bundschuh M, Goedkoop W, Kreuger I (2014) Evaluation of pesticide monitoring strategies in agricultural streams based on the toxic-unit concept-experiences from long-term measurements. Sci Total Environ 484:84-91. https://doi.org/10.1016/.ssitotenv.2014.03.015

58. van Toan P, Sebesvari Z, Bläsing M, Rosendahl I, Renaud FG (2013) Pesticide management and their residues in sediments and surface and drinking water in the Mekong Delta, Vietnam. Sci Total Environ 452-453:28-39. https://doi.org/10.1016/j.scitotenv.2013.02.026

59. BrackW, Aissa SA, Backhaus T, Dulio V, Escher BI, Faust M et al (2019) Effect-based methods are key. The European Collaborative Project SOLUTIONS recommends integrating effect-based methods for diagnosis and monitoring of water quality. Environ Sci Eur 31:5423. https://doi. org/10.1186/s12302-019-0192-2

60. Neale PA, Munz NA, Ait-Aïssa S, Altenburger R, Brion F, Busch W et al (2017) Integrating chemical analysis and bioanalysis to evaluate the contribution of wastewater effluent on the micropollutant burden in small streams. Sci Total Environ 576:785-795. https://doi.org/10.1016/j. scitotenv.2016.10.141

61. Posthuma L, Altenburger R, Backhaus T, Kortenkamp A, Müller C, Focks A et al (2019) Improved component-based methods for mixture risk assessment are key to characterize complex chemical pollution in surface waters. Environ Sci Eur 31:70. https://doi.org/10.1186/s12302-019-0246-5

62. Piha H, Dulio V, Hanke G (2010) River specific pollutants-identification and monitoring: workshop report. Luxembourg

\section{Publisher's Note}

Springer Nature remains neutral with regard to jurisdictional claims in published maps and institutional affiliations. 